\title{
A Database of Habitat Conservation Plans and Related Documents Developed Under the U.S. Endangered Species Act
}

\author{
Andrew Carter $^{1,2^{*}}$, Jacob Malcom ${ }^{1,2}$, Heather Harl ${ }^{1}$ \\ ${ }^{1}$ Center for Conservation Innovation, Defenders of Wildlife, Washington DC 20036 \\ ${ }^{2}$ Environmental Science and Policy Department, George Mason University, Fairfax, VA 22030 \\ * Correspondence \\ Andrew Carter \\ acarter@defenders.org
}

Keywords: Endangered Species Act, habitat conservation plan representation, threatened species, endangered species, diversity, ecosystem

\section{Abstract}

Under the U.S. Endangered Species Act, non-federal parties may be permitted to "take," or harm, listed threatened and endangered species provided they develop an appropriate "habitat conservation plan" that details how the applicant will minimize and mitigate the impacts of their activities on the species at issue. Despite widespread use of such plans, with more than 700 approved to date, there have been few systematic analyses to determine their effectiveness in protecting imperiled wildlife. This has been driven by a lack of a centralized repository of essential habitat conservation plan documents, from the plans themselves to required monitoring reports. Here we present a new data resource of 6,290 documents related to 601 separate HCPs, assembled through a United States Freedom of Information Act request to the U.S. Fish \& Wildlife Service, supplemented by web scraping of available HCP documents online. We describe the completeness of responses, characterize the scope of documents, and identify data and research gaps.

\section{Background and Summary}

The U.S. Endangered Species Act (ESA) is one of the most protective laws in the world for imperiled species, prohibiting "take" of all species designated as endangered and most species designated as threatened under Act. "Take" encompasses a broad range of actions that impact the species' health or behavior - including not only killing, but also harassment and disruption of activities such as breeding or feeding. Under section 10 of the ESA ("Exemptions"), the U.S. Fish and Wildlife Service ("FWS") or National Marine Fisheries Service ("NMFS," or collectively "the Services") are authorized to issue permits that would allow persons who inadvertently "take" a protected species to avoid legal liability. To receive one of these "incidental take permits" (ITPs), however, applicants are required to create - and get FWS to approve - a "habitat conservation plan" (HCP) that stipulates how the applicant plans to "minimize and mitigate" their impact on the species in question to the maximum extent practicable (16 U.S.C. $\S 1538(a)(2)(A)(i i))$. The HCP application process is shown in Figure 1. 


\section{HCP Application Process}

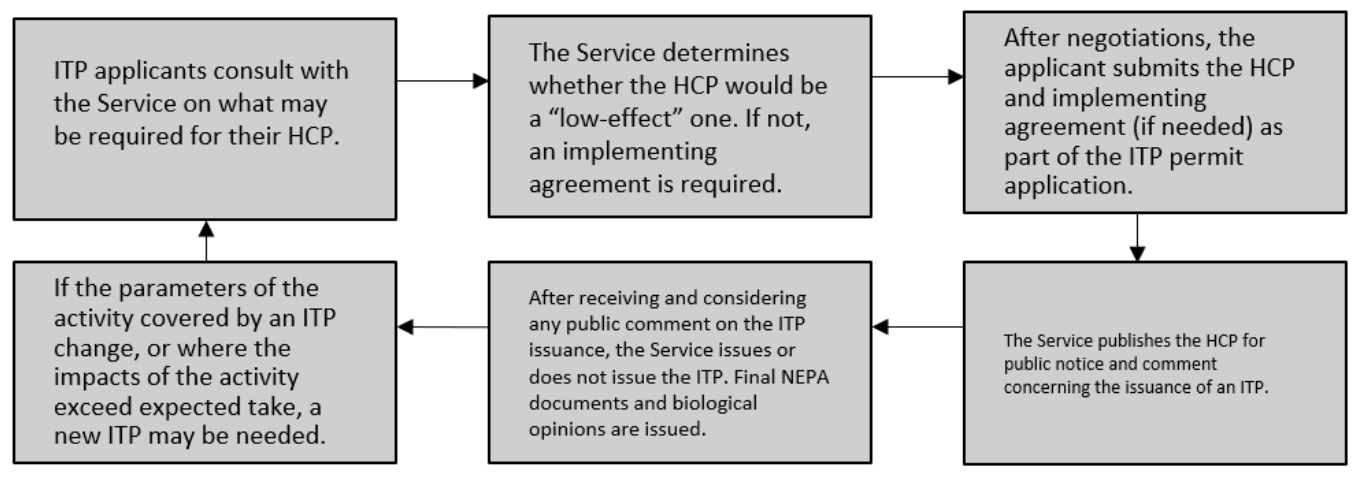

Figure 1. The process for submitting the HCP document and obtaining an incidental take permit under the U.S. Endangered Species Act.

Given section 10's stringent requirements for HCPs, the comprehensive evaluation process FWS are required to carry out, and the discretion offered them in deciding whether to approve or disapprove an ITP application, an ITP should only be issued when the HCP provides sufficient safeguards for the impacted species. However, despite the requirements of the law and the fact that the HCP program has existed for several decades, there remain significant questions as to whether the program is "mitigat[ing] and minimize[ing]" the impacts of covered activities on protected species.

Numerous critiques have been published of the program, and researchers, attorneys, and participants have criticized the HCP program for many perceived shortcomings. These include: its lack of centralized and adequate recordkeeping ${ }^{1,2}$; the lack of monitoring data generally,1; FWS failure to evaluate the aggregate take of protected species across multiple $\mathrm{HCPs}^{4,3}$; the lack of adequate baseline data on the species impacted ${ }^{5,2,6,7}$; the impact of the "no surprises" policy on species ${ }^{4,6}$; the prevalence of weak or unenforced HCP terms ${ }^{3,1}$; and insufficient adaptive management mechanisms ${ }^{2,8}$.

The overwhelming majority of HCPs are approved and administered by the U.S. Fish and Wildlife Service (FWS), which is the subject of this article. The FWS's HCP program is generally administered at the regional level, with regional headquarters or their local offices evaluating the HCP and issuing ITPs. FWS regions are shown in Figure 2. 


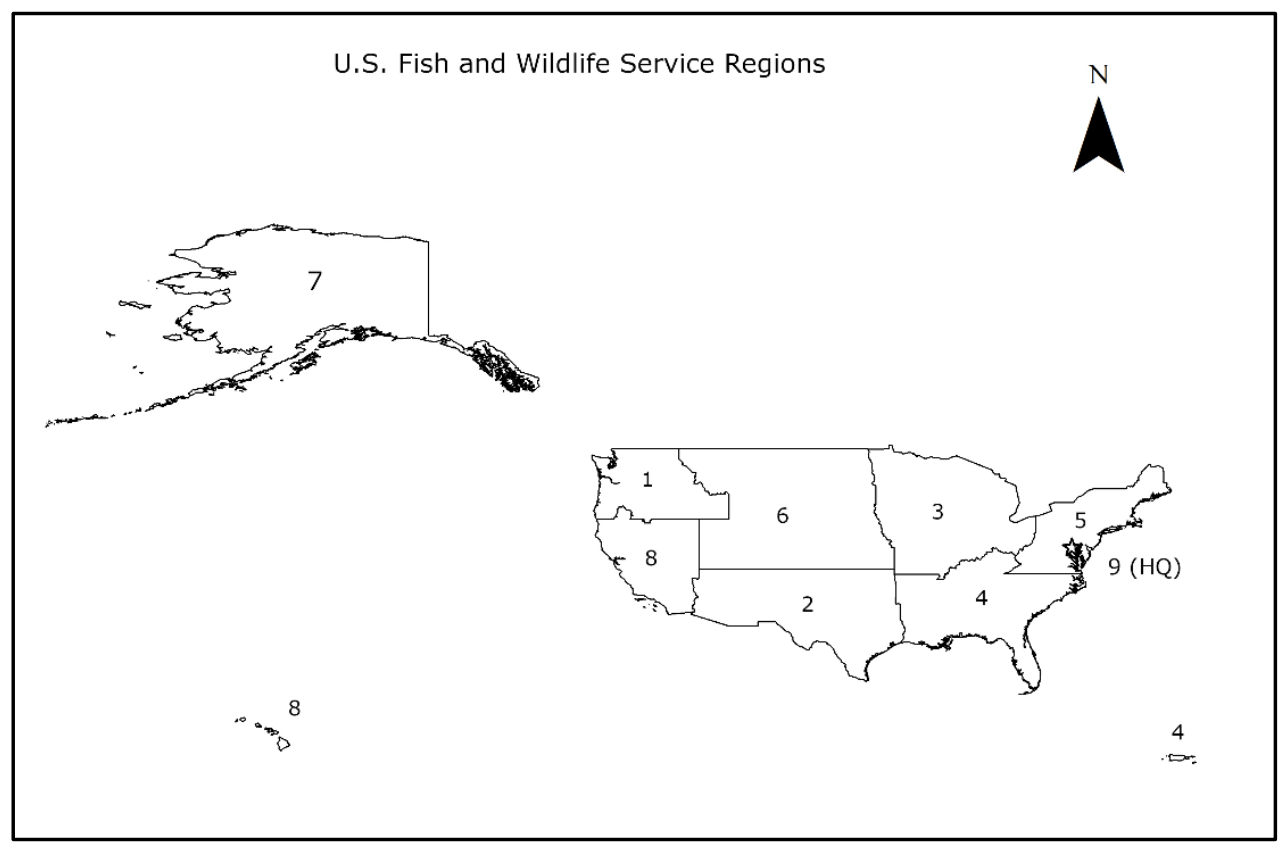

Figure 2. The U.S. Fish and Wildlife Service's traditional regions. Note that Region 9 in Washington, $D C$, covers national or multi-regional issues.

Currently, HCPs have been approved by FWS for more than 1,300 ITPs, covering numerous threatened and endangered species, and oftentimes significant areas, with some HCP project areas covering activities across more than one million acres of land ${ }^{9}$. Significant problems and inconsistencies with HCP recordkeeping and lack of access to HCP documents results in a significant information deficit as to the impact of either individual HCPs or the program on the species they are meant to protect ${ }^{1}$. The documents associated with the HCP process do not, unfortunately, always provide sufficient information to evaluate the efficacy of the HCP. For example, Owley ${ }^{1}$ found that the HCPs she examined - including the first HCP ever approved - did not always memorialize important information like details concerning mitigation measures. Thus, while ITP issuance might be conditioned on the applicant establishing a conservation easement on a parcel of land, the location and status of that easement might not be reflected in any of the HCP documents ${ }^{1}$.

The authors are aware of only one completed large-scale analysis of HCPs, which was conducted more than 20 years ago. With the assistance of wildlife organization partners, Kareiva et al. ${ }^{2}$ managed to obtain documents concerning 208 of the 225 HCPs existing at the time. They found significant information gaps in the dataset, including widespread lack of quantitative "take" estimates, substantial uncertainties as to whether given mitigation measures would be successful, and lack of clearly outlined monitoring programs ${ }^{2}$. Concerning HCP records, they also noted at the time that there was "no centralized office or collection of $\mathrm{HCPs}^{\prime 2}$. More than twenty years later, this lack of centralized document access still exists, even as the number of HCPs has increased dramatically.

\section{Methods}

Data were collected through two processes. First, we wrote a small web scraping utility and automated the download and organization of documents representing 139 HCPs from relevant FWS websites, including at headquarters and at the regional offices. Second, we filed a request for key documents for HCPs under the U.S. Freedom of Information Act (FOIA) to FWS, which manages almost all HCPs (with a 
small number managed by NMFS or jointly by both Services). We requested documents covering seven categories of documents (Table 1) from 655 separate HCP entries as identified in the FWS's ECOS database, created in December of 2017. We use FWS's delineation of individual HCPs, though its recordkeeping is inconsistent in terms of how such HCPs are categorized. For example, for some HCPs, the original HCPs/ITPs and amended HCPs/ITPs are grouped under one entry. In some cases one HCP can cover multiple permit applicants under "certificates of inclusion" and FWS may identify each certificate holder as a separate HCP. The FOIA request omitted, to the extent practicable, HCP entries for which adequate documents were available online, as well HCP entries that were determined to be amendments to an HCP for which documents (included amendments) were already requested. For programmatic or umbrella HCPs, we requested a random sample of $25 \%$ of HCPs created under those larger programmatic HCP. According to conversations with FWS, individual regions and offices were asked to collect and digitize documents responsive to the request and send them to headquarters. Documents were reviewed and some confidential information was redacted or omitted by FWS. The 655 $\mathrm{HCP}$ entries for which documents were requested represent the majority of all HCPs approved by FWS and include entries from the creation of the HCP program up until the date of request, December 6 , 2017. There are gaps in the dataset where FWS was unable to provide a document; missing document types are identified in the CSV file discussed in the data records section below. As of the time of writing, the repository has 6,290 files, related to 601 of the $655 \mathrm{HCP}$ entries for which documents were requested.

\begin{tabular}{|c|c|}
\hline Type Requested & ion \\
\hline $\begin{array}{l}\text { The final Habitat } \\
\text { Conservation Plan and any } \\
\text { amendments }\end{array}$ & $\begin{array}{l}\text { The HCP is the central document for incidental take permit applications; it } \\
\text { sets forth the steps the applicant will take to minimize and mitigate the } \\
\text { impacts of their actions on the affected species. The HCP is developed by } \\
\text { the applicant but must be approved by the U.S. Fish and Wildlife Service } \\
\text { before a permit is issued. The Service frequently requires the applicant to } \\
\text { adjust the HCP's terms before approval. }\end{array}$ \\
\hline The & $\begin{array}{l}\text { The signed ITP is the operative legal document providing protection from } \\
\text { the take prohibition of section } 9 \text { of the ESA. ITPs set forth the } \\
\text { responsibilities of the permit applicant as found in an approved HCP. If } \\
\text { there is any inconsistency between obligations in the HCP and obligations } \\
\text { in the ITP, the terms of the ITP control. }\end{array}$ \\
\hline $\begin{array}{l}\text { Monitoring reports for at } \\
\text { least the first three years and } \\
\text { most recent three years of } \\
\text { the HCP }\end{array}$ & $\begin{array}{l}\text { Many HCPs require permitholders to produce monitoring reports through } \\
\text { the life of the ITP showing compliance with the terms of the HCP and/or } \\
\text { the impact of the HCP on the protected species. }\end{array}$ \\
\hline The biological opinion & $\begin{array}{l}\text { The Biological Opinion is a document created through an ESA section } 7 \\
\text { consultation process. It provides the Service's evaluation of the project or } \\
\text { activity's impact on listed species, necessary conservation measures, and } \\
\text { reasonable and prudent alternatives to the actions contemplated. }\end{array}$ \\
\hline $\begin{array}{l}\text { The implementing } \\
\text { agreement }\end{array}$ & $\begin{array}{l}\text { An agreement between the applicant and the Service that sets forth more } \\
\text { detail in how the terms of the HCP will be implemented. Implementing } \\
\text { agreements are required by Service regulations for HCPs that are not "low } \\
\text { effect." }\end{array}$ \\
\hline $\begin{array}{l}\text { GIS files depicting the HCP } \\
\text { plan area and the permit } \\
\text { area }\end{array}$ & $\begin{array}{l}\text { While neither the ESA nor the implementing regulations require the } \\
\text { creation of GIS files, some HCPs do have associated GIS files showing the } \\
\text { HCP/ITP area. }\end{array}$ \\
\hline $\begin{array}{l}\text { The Service's section } 10 \\
\text { findings and } \\
\text { recommendations memo }\end{array}$ & $\begin{array}{l}\text { A document created by the Service that memorializes the decision-making } \\
\text { process that led to the approval of an HCP and the issuance of an ITP. }\end{array}$ \\
\hline
\end{tabular}

Table 1. Endangered Species Act Habitat Conservation Plan document types requested. 


\section{Data Records}

Files are provided in the format in which they were produced by FWS or scraped from internet sources, but directories and subdirectories have been standardized to use the same structure and naming conventions. We organized files by region, individual HCP, and subdirectories representing the different categories of documents we requested. FWS administers some HCPs through collective actions; documents relating to multiple HCPs may be collected in the same directory where appropriate, and further information will be identified in the CSV file accompanying the repository. The file hierarchy is shown in Figure 3. Orphan documents we were unable to associate with a specific HCP were not placed in the repository, but will be incorporated as we determine their appropriate location. Some produced or scraped documents did not fall within the categories requested, and were placed in directories that represented the most relevant available category. For example, ITP application forms were placed in the "2_Final ITP" directory, while documents related to National Environmental Policy Act analyses were placed in the "4_Final BOs and Amendments" directory since such analyses are often carried out in conjunction with the consultation process that produces biological opinions. FWS produced some communications between permitholders (or their agents) and FWS regarding information, clarifications, or updates about the HCP; these have been filed under the "monitoring reports" category, even when not necessarily comprising formal monitoring reports. The top-level directory contains an up-to-date listing of each HCP entry in CSV format, in the filename "HCP.cSV," which lists which documents per HCP entry were produced. An additional text file, "HCP.log," will be updated as additional files are added to inform users as to what files have been added.

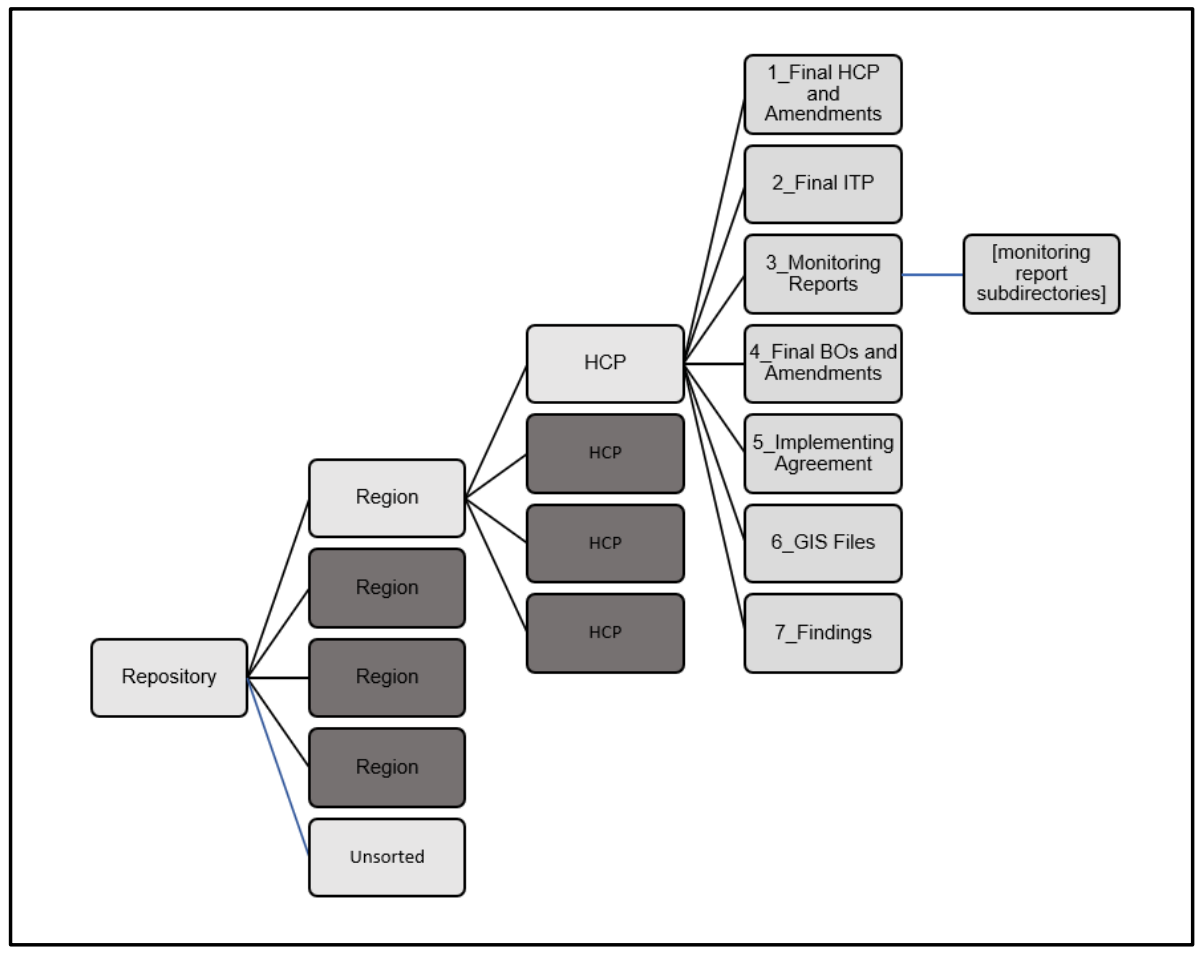

Figure 1. Schematic of the hierarchy of files in the repository. 
Validation and accuracy. Produced files were reviewed to ensure they were properly categorized in the appropriate directories and subdirectories. HCP entries were evaluated for the completeness of the file, and missing document types are identified in the "HCP.CSV" file.

Future updates. The repository will be updated as necessary moving forward if FWS produces additional documents, or additional documents are found on internet searches.

\section{Usage notes}

The documents in this database comprise the best available data at this time on HCP implementation in the U.S., but users should be aware of three main limitations.

First, while we have requested the full set of data for all HCPs described above-a mixture of census and random sample approaches - the records produced to us are incomplete. For example, we find that 645 (98\%) HCPs lack one or more category of requested document, though this does include some documents which are not required to be created for all HCPs (implementing agreement, GIS files) but that may be created. Of the documents of which are required under the applicable law and regulations to be created (the HCP document itself, ITP, biological opinions and findings) one or more such documents are missing for 168 out of 655 (26\%) HCPs for which they were requested. Specifically, FWS did not provide (and we could not obtain online): (1) the main HCP document itself for 99 out of 655 (15\%) HCPs; (2) the ITP for 105 out of 655 (16\%) HCPs; (3) the biological opinion for 108 out of the 655 (16\%) HCPs; and (4) the findings for 120 out of 655 (18\%) HCPs. This means FWS was unable to produce at least 432 documents out of the 2,620 (16\%) that would have had to have been created during the creation of these HCPs. This does not include other documents that may have been created but not produced, including implementing agreements, GIS files, and revised or amended versions of HCPs, ITPs, or draft and/or final versions of biological opinions. It is not clear at this time whether there is any underlying pattern of missingness that could introduce bias into any conclusions and inferences. We encourage users to independently evaluate the effects of missing data prior to drawing conclusions or making recommendations or presenting appropriate caveats and limitations. We would also note that FWS produced numerous duplicate documents; duplicates with the same filenames were removed, but those that had different filenames were retained.

Second, while the technical quality of the documents in the database will be updated on a regular basis as we continue to develop the resource, we cannot guarantee the accuracy or presence of particular machine-readable data. For example, some older documents may be scans that lack a text layer, or the scans may be low quality and any optical character recognition outputs may be suspect. We encourage users to practice due diligence in validating any data extracted using automated means.

Last, the repository includes many monitoring reports and files that represent fragments of larger documents that do not have identifying characteristics. We have proceeded under the assumption that FWS has accurately placed documents without HCP identifier information in the appropriate directory. For documents without identifiers produced outside a specific HCP directory, we made our best guess as to the appropriate HCP to which it belonged using document context and our knowledge of other documents related to that HCP. 


\section{Acknowledgements}

The authors are extremely grateful to FWS personnel who helped fulfill the FOIA request that made this project possible.

\section{Author Contributions}

A.C. and J.M. contributed to the design and implementation of the research and the writing of the manuscript. H.H. contributed to the development and analysis of the dataset and with the preparation of the manuscript.

\section{Competing Interests}

The authors declare no competing interests.

\section{References}

1.Owley J. Keeping track of conservation. Ecol. L.Q. 42:79-138. (2015).

2.Kareiva $\mathrm{P}$ et al. . Using Science in Habitat Conservation Plans. National Center for Ecological Analysis and Synthesis HCP Working Group. (2000).

3.Hall DA. Using habitat at conservation plans to implement the Endangered Species Act in Pacific Coast Forests: Common problems and promising precedents. Envtl. L. 27. (1997).

4.Duggan P. Extinction: How the Endangered Species Act's Incidental Take Permits Fail to Account for Population Loss. Envtl. L. R. 41:10628. (2011).

5.James C. Lessons Learned from a Study of Habitat Conservation Planning. Policy Forum 49:871-874. (1999).

6.Shilling F. Do habitat conservation plans protect endangered species. Science 276:1662-1663. (1997).

7.Thomas GA. Where property rights and biodiversity converge part III: Incorporating adaptive management and the precautionary principle into HCP design. Endangered Species Update 18:32-40. (2001).

8. Wilhere GF. Adaptive management in habitat conservation plans. Conservation Biology 16:20-29. (2002).

9.U.S. Fish and Wildlife Service (FWS). Conservation Plans Region Summary HCP. (ECOS, Environmental Conservation Online System). https://ecos.fws.gov/ecp/report/conservationplans-region-summary?region=8\&type $=$ HCP. . (2021). 